\title{
El Dios de las batallas: el providencialismo en la cronística hispana en la batalla de las Navas de Tolosa (1212)
}

\author{
Raimundo Meneghello Matte ${ }^{1}$ \\ Recibido: 20 de abril de 2015 - Aceptado: 25 de mayo de 2015
}

\begin{abstract}
Resumen
En el siglo XIII, las crónicas muestran una consolidación de los tópicos providencialistas, especialmente respecto de uno de los acontecimientos centrales de la Reconquista: la batalla de Las Navas de Tolosa de 1212. Para los cronistas, este evento reúne todos los elementos del providencialismo: una batalla entre la alianza de los cristianos contra el Islam y que mostró las pericias de un rey pecador, Alfonso VIII, que logró la redención. Por lo demás, los relatos son abundantes en milagros y otros sucesos que sirvieron para convertir a la batalla en un ícono del providencialismo. No obstante, debemos destacar que estos episodios providenciales evidencian cambios en relación a la forma en que habían sido presentados anteriormente, dado que se trataría de portentos menos espectaculares. Se relatan pequeños milagros que en su conjunto componen una gran historia providencial; a su vez, la mano de Dios es menos directa, resaltando en su lugar las acciones de los hombres, siempre bajo la premisa de que sus actos eran impulsados por la Providencia.
\end{abstract}

Palabras clave: Reconquista, Providencialismo, Navas de Tolosa, Alfonso VIII

\section{The god of battles: providentialism in the hispanic chronicle in the battle of las Navas de Tolosa (1212)}

\begin{abstract}
In the Thirteenth century, chronicles show a consolidation of the providential topics, especially on one of the central events of the Reconquista - the battle of Las Navas de Tolosa in 1212. For historians, this event brings together all the elements of Providentialism: A battle between the alliance of Christians against Islam showing the skills of a sinner King Alfonso VIII, who achieved
\end{abstract}

Chileno. Doctor en Historia Medieval, Universidad de Salamanca, España. Este trabajo es parte de mi tesis doctoral titulada "Tópicos y continuidades en el discurso sobre la expansión y en la reafirmación de la monarquía castellana (siglos XII y XIII): Una propuesta de Análisis de la cronística en la Reconquista". Académico Universidad Finis Terrae, Chile. E-mail: raimundomeneghello@gmail.com 
redemption. Furthermore, stories abound in miracles and other events that served to turn the battle into a Providentialism icon. However, we must emphasize that these providential events show changes in relation to how they had been presented before as they would be less spectacular wonders. Small miracles which jointly make up a large providential history are recounted; the hand of God is less direct, highlighting instead the actions of men, under the premise that their actions were driven by Providence.

Keywords: Reconquista, Reconquest, Providentialism, Navas de Tolosa, Alfonso VIII

\title{
0 deus das batalhas: o providencialismo na crônica hispana na batalha das Navas de Tolosa (1212)
}

\begin{abstract}
Resumo
No século XIII, as crónicas mostram uma consolidação dos temas providencialistas, especialmente referente de um dos acontecimentos centrais da Reconquista: a Batalha das Navas de Tolosa em 1212. Para os cronistas, este evento reúne todos os elementos do providencialismo: uma batalha entre a aliança dos cristãos contra o Islão, mostrando as habilidades de um rei pecador, Alfonso VIII, que logrou a redenção. Além disso, os relatos abundam em milagres e outros sucessos que serviram para transformar a batalha num ícone do providencialismo. Porém, deve-se destacar que estes episódios providenciais mostram mudanças em relação à forma que tinham sido apresentados anteriormente, devido a tratar-se-ia de maravilhas menos espetaculares. Relatam-se pequenos milagres que no seu conjunto, compõem uma grande história providencial; por sua vez, a mão de Deus é menos direta, ressaltando no seu lugar as ações dos homens, sob a premissa de que suas ações foram impulsionadas pela Providência.
\end{abstract}

Palavras-chave: Reconquista, Providencialismo, Navas de Tolosa, Alfonso VIII

\section{Reconquista y Providencialismo}

El proceso de la Reconquista Hispánica, comprendida como el periodo de enfrentamiento y convivencia entre cristianos y musulmanes en la Península Ibérica, entre los siglos VIII y XV, constituye un elemento clave para la comprensión de la historia de España y por extensión de Occidente, con proyección a la época Moderna y posteriores ${ }^{2}$. Se trató de un extenso proceso que permite observar la evolución de los distintos elementos característicos de la mentalidad

2 Aunque a nivel general suele situarse a la Reconquista entre los siglos VII y XV, actualmente existe cierto consenso entre los especialistas, que ubican el inicio del proceso en torno al siglo XI luego del colapso del Califato de Córdoba. 
hispánica medieval reflejada en las crónicas y fuentes del periodo, tales como el pensamiento goticista, el providencialismo, la guerra, la frontera, el cautiverio, el intercambio cultural y la consolidación monárquica, solo por nombrar algunos.

En ese marco es que los siglos XII y XIII fueron los de mayor actividad reconquistadora, época en la que se desarrolló la llamada "España de los cinco reinos" (Castilla, León, Aragón, Portugal y Navarra) y el al-Andalus, que durante ese periodo fue dominado sucesivamente por las Taifas, el Imperio Almorávide, las Segundas Taifas y el Imperio Almohade 3 . Es así como la Reconquista debe ser entendida como reflejo de las dinámicas de una sociedad de frontera entre dos culturas-religiones opuestas, por lo que todo el enfrentamiento y convivencia, con sus periodos de guerra y treguas, se encontraba inmerso en una cosmovisión providencialista.

En este contexto pretendemos presentar el caso del providencialismo en torno a la batalla de las Navas de Tolosa. Utilizamos como eje central el discurso providencialista y su relación con el poder político, en el entendido de que para los soberanos hispanos, y de Europa en general, era importante demostrar que tenían el favor de Dios como una forma de validación de su poder y para ello contaban con la ayuda de los cronistas que plasmaron en sus relatos un discurso en el que señalaban todos aquellos elementos en que el juicio de Dios beneficiaba al soberano.

Pero antes de entrar directamente al análisis de este problema, consideramos prudente realizar una breve explicación respecto a las batallas campales en la Edad Media. Partimos del hecho de que, pese a lo que dan a entender las fuentes, la gran batalla era un acontecimiento extraordinario y excepcional, puesto que una derrota podía decidir no solo la guerra sino que el destino de un reino. Eran, por lo tanto, un riesgo que se prefería evitar. En relación a lo mismo la batalla compartía las características de una ordalía, es decir, un encuentro entre iguales para dirimir una disputa donde Dios se pondría de parte del vencedor, demostrando así las virtudes de éste. En vista de ello, habitualmente los cronistas exageraban sus relatos dándoles a los combates tintes dramáticos y fantásticos, como parte del discurso cronístico de exaltar o denostar a un bando y otro 4 .

Complementario a lo anterior, la presencia de la divinidad, mediante apariciones o milagros, en los hechos de armas cristianos, es un tópico rela-

3 A modo de orientación general, la cronología del al-Andalus puede dividirse en Califato de Córdoba (929-1031), Primeras Taifas (1031-1085), Imperio Almorávide (1085-1144), Segundas Taifas (1144-1172), Imperio Almohade (1172-c1230) y, finalmente, Terceros reinos de Taifas.

$4 \quad$ En relación a las formas de guerra del mundo medieval y en especial para el escenario peninsular recomendamos revisar, entre otros, los trabajos de Francisco García Fitz (2001, 2002, 2003, 2008); Philippe Contamine (1984); y Maurice Keen (2005). 
tivamente común en las fuentes del periodo, y puede ser visto casi siempre en relación a alguno de los siguientes elementos: 1) intervenciones directas de Dios o el Espíritu Santo para influir, favorecer o castigar a los hombres; 2) apariciones de santos o mensajeros celestes; y 3) ejércitos celestiales que participan directamente en las batallas por el bando cristiano. Asimismo este tipo de providencialismo era parte de una tradición que encuentra sus raíces directas en el Antiguo Testamento, en especial en el Éxodo y los llamados Libros Históricos, como Josué, Jueces, Judit y Macabeos.

Para el caso cristiano-hispánico las intervenciones providenciales aparecen durante el periodo del Reino Visigodo, pero se hacen más frecuentes después de la invasión islámica del 711. En primera instancia, se asumió esta invasión como un castigo divino por los pecados de los visigodos y, luego, como señal de reconciliación a partir de los relatos míticos de las batallas como las de Covadonga y Clavijo.

Es fundamental, eso sí, destacar que para el caso de la cronística medieval no debemos juzgar todos los relatos providenciales como meras invenciones propagandísticas, puesto que las apariciones de santos y otros milagros eran parte del imaginario colectivo de la sociedad medieval y, por ende, fruto de una tradición que rara vez era rebatida por los contemporáneos.

\section{Las Navas y sus fuentes}

Dentro de este contexto ideológico cultural, la batalla de las Navas de Tolosa del 16 de julio de 1212 es uno de los acontecimientos fundamentales de la Reconquista Hispánica, ya que señala un punto de inflexión en la guerra contra el al-Andalus. A partir de este enfrentamiento, el imperio Almohade comenzó su colapso en la Península y los andalusíes fueron anulados militarmente y obligados a adoptar una posición defensiva. Se define además el punto de partida para las posteriores exitosas campañas de Fernando III (1217-1252) y la política de expansión de Alfonso X (1252-1284).

Por todo lo anterior, la batalla es ampliamente destacada en las fuentes de la época y en las inmediatamente posteriores, contándose, entre otras, las cartas de Alfonso VIII de Castilla a Felipe II de Francia (octubre 1211) y a Inocencio III (agosto -septiembre 1212), la misiva de Berenguela de Castilla a su hermana Blanca, princesa de Francia (julio-agosto 1212), y las epístolas del califa al-Nasir relatando la conquista de Salvatierra (septiembre 1211) y la batalla de las Navas (julio 1212).

Respecto a las crónicas, destacan Los Anales Toledanos / y II (de mediados del siglo XIII), el texto de Lucas de Tuy, Chronicon mundi (1236), la crónica de Rodrigo Jiménez de Rada (quien además participó personalmente en la 
batalla), el De Rebus Hispaniae (escrito entre 1241 y 1242), la Crónica Latina de los Reyes de Castilla (compuesta entre 1226 y 1236), la alfonsina Crónica General de España (de finales del siglo XIII) y la Crónica de veinte reyes (compuesta entre 1270 y 1289). En todas estas fuentes, como es común para eventos de esta magnitud, se ve una importante exageración propagandística, aumentando notablemente los números de combatientes, en especial los referidos a los enemigos y a los muertos, y además editando los acontecimientos para que se adaptaran a la ideología del bando triunfador, en este caso los cristianos y la Iglesia ${ }^{5}$.

Todo ello, en concordancia con los testimonios de la época y los estudios actuales, en los cuales existe el consenso en que la campaña de las Navas de Tolosa fue una cruzada formal, dentro del contexto de la Reconquista ${ }^{6}$.

5 La historiografía también ha escrito bastante sobre este acontecimiento, destacando José Goñi (1958), Ambrosio Huici Miranda (1956), Carlos Vara Thorbeck (1999), Martín Alvira Cabrer en su tesis doctoral y en distintos artículos (1995, 1996, 1997), Manuela García Pardo (2002), y Francisco García Fitz (2005), solo por mencionar algunos.

$6 \quad$ En vista de lo anterior, creemos que es prudente puntualizar que para los pensadores medievales la Cruzada, con cualquiera de sus nombres, era una realidad sobre la cual, aparentemente, no se realizó una discusión teológica al nivel de la efectuada en torno a la Guerra Santa. Por lo mismo, aventuramos que para los intelectuales contemporáneos la cruzada fue interpretada como la evolución o la continuación de la Guerra Santa, más que un fenómeno totalmente nuevo, al menos para los siglos estudiados. Un planteamiento que creemos compartir con Riley-Smith cuando afirma que "Desde luego, el problema radicaba en que las cruzadas se convirtieron en un elemento tan conocido del paisaje medieval que no requería una descripción detallada. Las personas que vivieron en esa época sabían perfectamente lo que era una cruzada. En los escritos de los cronistas, de los apologistas y los canonistas, así como en las expresiones empleadas por quienes redactaban cartas papales, podemos identificar las señales que informaban a los fieles que se estaba predicando una cruzada" (Riley-Smith, 2012). Para una panorámica general en torno a estas discusiones y las distintas posturas, recomendamos ver, entre otros textos relacionados al tema, los trabajos de Frederick Russell y su texto clásico The Just War in the Middle Ages, donde la Cruzada es comprendida como un hibrido entre la Guerra Justa y la Guerra Santa, cada vez más controlado y que como tal, será tratado como un todo por la filosofía cristiana: "Hence the crusade became a strange hybrid of holy war and just war marked by an increasingly explicit chain of command. The holy war and the crusade will here be considered only as a part of the general medieval debate of the right to war rather than as an independent phenomenon" (Russell, 1977: 2). Junto a él y ya tratando de elaborar una definición más compacta, encontramos a Antonio García y García, que define cruzada como "una guerra promovida o bendecida por el Papa o por su representante, cualificada de espiritualmente meritoria y, por ende, premiada con la indulgencia plenaria de los pecados de quienes cumplieran su voto de cruzados en alguna de las expediciones para la recuperación de los santos lugares de Palestina o de la Península Ibérica o para otras causas declaradas por los papas como cruzadas" (García, 1985: 222). Destacando, adicionalmente, que este autor postula la importancia del I y II Lateranense en la caracterización formal del término y agregando, al mismo tiempo, a su difusión original la afirmación de que el fenómeno se origina a partir de Urbano II y que, por lo tanto, es inseparable de la iniciativa pontificia. Complementando a García, podemos identificar a Ricardo García Villoslada que presenta una definición muy similar pero destacando el carácter pontificio y supranacional de la 


\section{Contexto: Alfonso VIII, Reconquista y Cruzada}

A comienzos del siglo XIII, bajo el reinado de Alfonso VIII (1158-1214), Castilla había comenzado a destacar en el contexto peninsular, pese a sus constantes enfrentamientos con los reinos cristianos vecinos y, en especial, León y su rey Alfonso IX (1188-1230). Por su parte, el al-Andalus se encontraba sometido a los Almohades, al mando del Califa Abu Yaqub Yusuf alMansur, quien en 1195 inició una serie de ofensivas contra tierras castellanas, derrotando a Alfonso VIII en el desastre de Alarcos el 19 de julio de 11957.

Alarcos fue el inicio de una serie de acontecimientos que redefinirían la historia de la Reconquista. Ante el peligro del avance de Yusuf al-Mansur, los monarcas de Navarra, Aragón y León acudieron al auxilio de Alfonso VIII. Pero el castellano decidió no esperar a los refuerzos y se enfrentó en solitario a los musulmanes, resultando la operación en el desastre de Alarcos.

Para los cronistas, la derrota tuvo explicaciones simbólicas y providencialistas. El rey había cometido dos graves pecados que le restaban la Gracia de la Providencia y precipitaron su infortunio (García F., 1988: 54-55): el primero fue la soberbia, ya que se había atrevido a creer que podía prescindir de la

campaña: "el nombre de 'Cruzada' se debe reservar exclusivamente a aquellas guerras santas predicadas y en cierto modo dirigidas por el Papa en cuanto cabeza y jefe de toda la cristiandad. Tienen, consiguientemente, un carácter supranacional y universal, y por eso suelen participar en ellas soldados de diversas naciones cristianas" (García V., 1967: 433). Extendiendo su ejecución más allá de Jerusalén, están autores como Geoffrey Hindley en su texto Las Cruzadas, peregrinaje armado y guerra santa (2005) que destaca cómo la cruzada fue utilizada contra el conjunto de los enemigos de la Iglesia, sean estos cismáticos, herejes, paganos o musulmanes. En tanto que José Manuel Rodríguez García (1994) realiza una definición bastante amplia donde procura incorporar la Reconquista dentro del contexto ideológico cruzado: "Una cruzada era una guerra santa autorizada por el Papa, quien la proclamaba en el nombre de Dios o Cristo. Se creía que era una empresa emprendida por Cristo, legitimizada por su mandato personal. Propuesta, como todas las acciones cristianas de violencia justa, como una respuesta defensiva a la injuria o a la agresión o como un intento de recobrar territorios cristianos perdidos a manos de los infieles, contestaba a las necesidades de la Iglesia de toda la Cristiandad, concebida como un estado único, universal y transcendente, más que una nación o región particular: muchas de las campañas de la Reconquista española, que se lucharon en nombre no sólo de España sino de la Cristiandad al fin y al cabo y que se abastecieron de hombres provenientes de toda Europa, eran cruzadas." (Rodríguez, 2002). Finalmente, Franco Cardini (2003) no realiza una definición concreta de cruzada y de hecho afirma que la Iglesia nunca elaboró una propia, pero analiza el tema desde sus orígenes en la guerra santa, la paz y tregua de Dios y la Reforma Gregoriana, agregando al discurso religioso los factores políticos, sociales y económicos que contribuyeron a su popularidad en el medioevo.

7 La derrota de Alarcos fue el primer gran revés cristiano en campo abierto desde la batalla de Uclés en 1108, y puso en entredicho la legitimidad de Alfonso VIII, que luego de ella debió enfrentarse nuevamente a sus vecinos cristianos que buscaban resarcir sus antiguas pérdidas, al mismo tiempo que trataban de contener la ofensiva almohade (García Fitz, 2008: 120-121). 
ayuda de los otros reinos cristianos, y en un impulso de orgullo injustificado, se lanzó imprudentemente a conquistar la gloria; fue un acto de desprecio a la humildad y piedad que debían caracterizar a un rey cristiano. Al respecto la Crónica Latina señala:

"Ignis ascensus uidebatur in furore Domini et elationem animi, si qam conceperat rex nobilis ex gloria precedenti, deprimere uidebatur, ut intelligeret rex prudens et nobilis quod regnum filiorum hominum in manu Dei est et cuicumque uoluerit dabit illud" (Crónica Latina de los reyes de Castilla, 1997 [s. XIII], 14: 48)8.

Esta versión es reforzada por el autor de la Crónica de veinte reyes, quien no duda en afirmar que "mas non quiso Dios que los chistianos saliesen ende onrrados, que non eran de vn coraçón nin ayudaron a su señor commo deuían, e fueron vençidos e malandantes e murieron y muchos cristianos" (Crónica de veinte reyes, 1991 [s.XIII], XIII, 25: 280).

En ambos casos los testimonios no dejan dudas, Alfonso y sus huestes no contaron con la protección de la Providencia, que airada por la actitud del monarca, dejó que éste fuese vencido por sus enemigos.

Asimismo, podemos observar en las mismas fuentes que Alfonso no sólo atrajo la ira divina sobre él mismo, sino también sobre toda la comunidad. El castigo fue para el conjunto de los castellanos que no lucharon o auxiliaron a su señor como debían hacerlo. Esto se hace extensivo para el resto de los cristianos, como lo indica la Crónica Latina, que afirma que Alfonso de León no llegó con ayuda a la batalla de Alarcos, debido al "consejo de algunos satélites de Satanás" (Crónica Latina de los reyes de Castilla, 1997 [s. XIII], 14: 47). Esta es una explicación providencialista y política a la vez, puesto que justifica la derrota de Castilla apelando a la intervención del Mal y al mismo tiempo, acusa al rival de Alfonso VIII de traicionar a su primo, al dejarse influenciar por el demonio. Dicha acusación equivale a señalar al rey de León como un hombre traicionero, entendido en el contexto de disputas que afectaba a ambos reinos y al interés de los cronistas por favorecer a los bandos según su origen.

Junto a la soberbia, el segundo pecado del rey castellano fue el hecho de que se encontraba en falta en el momento de iniciar la campaña, por haber engañado ${ }^{9}$ a su legítima esposa, Leonor de Plantagenet, con una amante

8 "El fuego de la ira del Señor parecía crecer y abatir la soberbia, que quizá tuviese el noble rey por su gloria anterior, para que entendiera el prudente y noble rey que el reino de los hombres está en manos de Dios y lo da a quien quiere." (Crónica Latina, 1999 [s. XIII], 14: 40).

9 Si bien la posesión de concubinas no era extraño en los reyes cristianos, siempre fue una situación incómoda, que se trataba de no ventilar, puesto que era una grave falta al sacramento matrimonial. 
judía ${ }^{10}$. Una falta agravada por el hecho de que su favorita era miembro de un pueblo hacia el cual solían dirigirse recelos y acusaciones de corte religioso. En otras palabras, el rey se encontraba en pecado y había atraído la ira de Dios, que lo había castigado con la derrota militar, al igual que lo había hecho con los reyes del antiguo Israel ${ }^{11}$.

Los pecados del rey, la soberbia y la lujuria, incluso trascendieron de la Península y atrajeron voces críticas contra la actitud del soberano, que por sus actos ponía en riesgo la muy noble misión de combatir al Islam, y permitía el aumento de las fuerzas de los poderosos almohades. Esto se evidencia en una de las obras del trovador y posterior Obispo, Fulco de Marsella, quien amonesta al rey por su conducta ${ }^{12}$.

La derrota de Alfonso VIII, justo en un momento de conflictos entre los monarcas cristianos peninsulares, desató una serie de luchas entre los reinos hispanos y favoreció el avance de los musulmanes, el que no obstante se detuvo prontamente en razón del agotamiento de los esfuerzos de los almohades, lo que permitió a los castellanos reorganizar sus fuerzas y contener a sus vecinos.

La idea de un castigo divino como explicación al desastre de Alarcos encontró eco en el mismo Alfonso VIII. Según García Fitz, el rey cambió su actitud luego de la derrota, enmendando su conducta y renegando de sus pecados. Ello en la lógica cristiana de que si una mala acción era motivo de castigo divino, su enmienda atraería el favor de la Providencia (García, 1988: 54-55).

Paralelamente a estos hechos, Alfonso VIII había logrado restablecer el orden en su reino y firmado una tregua con los almohades. Aún así -en versión de distintos cronistas- el rey se encontraba profundamente afectado por su descalabro en Alarcos, al punto de que la idea de una revancha se había convertido prácticamente en una obsesión ${ }^{13}$. Algo que no es de extrañar, si recordamos que para la visión providencialista la derrota era interpretada

10 Este episodio es destacado por García Fitz (1988). Aquí el autor expone que en la edición de la Primera Crónica General de Florián Ocampo, se rescata la presencia de la amante judía de Alfonso VIII, que no aparece en la edición de Pidal. En el episodio se narra cómo la amante fue ultimada por los hombres del rey, que consideraban que dicha relación era perjudicial para todo el reino. Un acto que entristeció al rey, lo que implicó que un ángel le advirtiera que sus actos y actitud atraerían el castigo divino (García Fitz, 1988: 54-55).

11 En el Antiguo Testamento existen diversos episodios en los que se relata cómo Dios castigó a los soberanos de Israel por sus pecados. Emblemáticos son los casos de Saúl y David.

12 Un reproche no menor viniendo de él, que como obispo a partir de 1205, jugó un rol importante en la lucha y persecución contra los albigenses en Francia (Alvar, 1977: 95).

13 Al respecto la Crónica Latina nos dice "Manebat in alta mente regis positum, quod nunquam de ipsa exciderat: infortunium quod passis fuerat in bello de Alarcos. Sepe reuocabat ad animun diem illam, habens desiderium uicem reddere regi Marroquitano et pro hac re sepe Dominum deprecabatur." (Crónica Latina de los reyes de Castilla, 1997 [s. XIII], 18:53). 
como el fracaso ante un juicio divino. Parecía entonces que Dios había abandonado al monarca por sus pecados, y por ello había sido puesto en entredicho por sus enemigos. En consecuencia, el rey debía probar que era digno de su alto cargo, y sólo una victoria podría demostrar su reconciliación con la Providencia y legitimarse ante sus enemigos y súbditos.

Por todo ello, Alfonso comenzó a preparar su desagravio militar, empezando por crear un escenario favorable en la Península y en Europa; consciente de la necesidad de un esfuerzo mayor; comenzó a formar una alianza con sus vecinos y el papado. El castellano procuró difundir los peligros de la amenaza almohade por el continente, sirviéndose de una verdadera campaña de propaganda ${ }^{14}$.

La oportunidad de poner en acción sus planes se le presentó al rey de Castilla en 1211, cuando, finalizadas las treguas, una nueva ofensiva Almohade, liderada por el nuevo Califa Muhammad Al-Nasir, el Ilamado Miramamolín, se apoderó del castillo Salvatierra. Un hecho que significaba una gran amenaza para toda la Península.

Alfonso VIII solicitó al papa Inocencio III (1198-1216) una bula de cruzada, que le fue concedida ${ }^{15}$. Al mismo tiempo, el Papa exhortaba a todos los señores, monarcas y autoridades religiosas peninsulares a apoyar el esfuerzo bélico y amenazaba con la excomunión a cualquiera que se aprovechase de la ocasión para atacar a Castilla durante la campaña. Finalmente, el Papa también ordenó a los prelados franceses que predicasen la Cruzada Hispánica por las tierras de los francos (Rodríguez L., 1988: 19; Rodríguez G., 2002: 582).

14 Entre los instrumentos que utilizó Alfonso se destacaron el capítulo general del Císter y los trovadores. La orden monástica con sus redes de influencia política e intelectual ayudó a difundir el mensaje en las esferas de poder europeas, apelando a la lucha contra los enemigos de Dios. En tanto que los trovadores, con sus obras, conmovieron a las Cortes de Francia, recalcando el peligro del avance moro en Hispania. Así, los guerreros francos eran exhortados desde los altares y los palacios para ir a buscar la gloria al servicio de Dios. Una táctica que al parecer surtió efectos, como veremos más adelante, cuando Alfonso dé inicio formal a la campaña de las Navas (Alvira, 2006: 193).

15 Hay indicios de que el Papa no confiaba plenamente en los resultados de la próxima campaña. Al parecer el Pontífice dudaba de lo oportuno de la misión y, en especial, temía la merma que esta nueva cruzada podía generar entre los combatientes provenzales que luchaban contra los albigenses. Por estas razones, el pontífice aconsejó a Alfonso VIII aceptar una tregua si es que ésta era ofrecida por los Almohades y postergar la campaña para un momento más propicio (Huici Miranda, 1956: 229). Pero al perseverar el castellano en sus intenciones, el Pontífice emitió una serie de documentos mediante los cuales patrocinaba la campaña, aunque sin comprometer el envío de un legado o de recursos extraordinarios. Respecto a estos documentos, Mansilla, en su recopilación de documentos pontificios hasta Inocencio III, reúne entre otros: un mandato al arzobispo de Sens para prestar auxilio a Alfonso VIII (Letrán, 31 de enero de 1212), Notificación al rey de Castilla sobre el mandato anterior (Letrán, 4 de febrero de 1212), Ordena a los arzobispos de Toledo y Compostela a obligar a los reyes hispanos a hacer la paz y unirse contra el Islam (Letrán, 5 de abril de 1212), manda realizar rogativas en Roma por el éxito de la cruzada (Letrán, 16 de mayo de 1212). 
Gracias a la intervención papal, Alfonso VIII pudo pactar treguas con todos sus adversarios peninsulares, además de forjar alianzas, puesto que las promesas espirituales, sumadas a la esperanza de la obtención de un gran botín en caso de victoria, influyeron para que los reyes de Navarra, Sancho VII (1194-1234) y de Aragón, Pedro II (1196-1213), se sumasen a la campaña, mientras que el rey de Portugal, Alfonso II (1211-1223), otorgó libertad de acción a sus vasallos para que se sumasen a la cruzada.

Para aunar más fuerzas, Alfonso VIII aprovechó la bula de cruzada para enviar al arzobispo de Toledo, Rodrigo Jiménez de Rada, a la corte de Felipe II de Francia, para invitarlo a unirse a la campaña bajo las promesas de expiación cruzada y el botín. Pero el monarca franco no estaba dispuesto a arriesgarse en las lejanas tierras extremeñas, más cuando su propio reino se hallaba en una cruzada contra los herejes albigenses ${ }^{16}$.

No obstante, Jiménez logró convencer a numerosos señores francos, entre ellos los obispos de Narbona, Burdeos y Nantes, que aportaron unas fuerzas que según las crónicas sumaban alrededor 40 a 60 mil hombres, aunque las cifras modernas los han reducido a alrededor de 15.000 guerreros. De todas formas un número significativo de hombres para la época.

Estos cruzados ultramontanos se suman a los guerreros castellanos, además de destacamentos portugueses, navarros, aragoneses, y a los de las Órdenes de Santiago, Calatrava, Temple y San Juan. Conformaron así una gran alianza peninsular, algo inédito en la guerra de Reconquista ${ }^{17}$.

\section{Camino a la batalla}

Forjadas las alianzas, en febrero de 1212 las tropas cristianas comenzaron a reunirse en Toledo. Es a partir de este momento que las fuentes cronísticas toman un matiz cada vez más providencialista en su discurso.

Ejemplos de ello los podemos observar en las palabras de Jiménez de Rada, que nos dice: "y aumentaba por días el número de los que lucían en su cuerpo la señal del Señor y reinaba la armonía entre ellos" (Jiménez de Rada, 1989 [s. XIII]: VIII, 2: 308). Sin embargo otras fuentes como los Anales Toledanos nos mencionan que los francos, venidos de la cruzada contra los

16 La cruzada albigense o cruzada contra los cátaros, fue la guerra desarrollada entre los años 1209 y 1244, por iniciativa del papa Inocencio III con el apoyo de la monarquía francesa, con el fin de reducir por la fuerza a la herejía albigense o cátara, en los territorios feudales del Languedoc.

17 Frente a ellos estaban las tropas del califa Muhammad Al-Nasir que. según cálculos actuales, duplicaban o triplicaban a los cristianos, es decir, tenían entre 40 a 60 mil hombres. 
cátaros, tuvieron fuertes roces con los judíos de Toledo a los que acosaron y atacaron, obligando la intervención de las milicias locales para asegurar la paz:

"Quando se perdió Salvatierra envío el rey D. Alfonso al arzobispo D. Rodrigo á Francia, é Alemaña, é al apostoligo de Roma, é dio el apostoligo á tal soltura por todo el mundo que fuesen todos soltos de sus pecados: é este perdon fue poque el rey de Marruecos dixo que lidiaria con cuantos adoraban cruz en todo el mundo, é moviendose los dultra puertos, é vinieron a Toledo en dia de Cinquesma, é volvieron todo Toledo, é mataron de los Judios dellos muchos, é armaronse los Caballeros de Toledo é defendieron a los Judios." (Los anales toledanos / y II, 1993: 172).

La omisión que hace Jiménez de Rada a estos enfrentamientos puede explicarse por una doble razón; primero, la de hacer patente la supuesta gracia divina, la que se manifestaba en la supuesta armonía existente entre los cruzados y, por otro lado, quizás, la de proteger su propia imagen como el responsable de reclutar a los ultramontanos.

El suceso de los judíos también refleja la particularidad de la realidad peninsular. Los guerreros francos eran hombres que provenían de la cruzada contra los albigenses, por lo tanto acostumbrados a una guerra santa más brutal y total contra los enemigos de la fe. En sus mentes era inconcebible la convivencia con los no cristianos, más si como los judíos de Toledo, se encontraban en una ventajosa posición económica.

Superados los altercados, el día 20 de junio los cristianos se pusieron en camino a la batalla; se iniciaba así la campaña y, con ella, una serie de milagros. Los cronistas procuraron demostrar cómo la Providencia protegió a los guerreros, como en el caso del cruce del río Guadiana, que los cristianos sortearon sin sufrir grandes percances, a pesar de haber sido sembrado de abrojos por los almohades (Alfonso X, 1977 [s. XIII], 1015: 695). Esto sirvió a los cronistas para afirmar que Dios protegía a los cruzados, y que ningún instrumento humano podría dañar a quienes contasen con su protección, como nos relata Jiménez de Rada:

"Set quia humana artificia contra Dei prouidenciam nichil ualent, sic Deus uoluit ut paucissima uel nulli fere illis tribulis lederentur; et gracie Dei manu supposita transiuimus flumen Anam et castramentati fuimus in circuitu Calatraue" (Jiménez de Rada, 1988 [s. XIII]: V: 264) ${ }^{18}$.

18 "Pero como las invenciones de los hombres nada pueden hacer contra la providencia de Dios, la voluntad de Dios fue que escasísimos, o casi ninguno, se hiriera con aquellos abrojos; y sobre la mano de la Gracia de Dios, a modo de puente, atravesamos el río Guadiana y acampamos en derredor de Calatrava." (Jiménez de Rada, 1989 [s. XIII]: VIII, 5: 313). 
Nótese que el arzobispo no afirma la inutilidad de los abrojos y que, por el contrario, reconoce que algunos guerreros resultaron lastimados, lo que hace más interesante su discurso, puesto que intenta dar a cada dificultad una explicación providencial que refuerce las motivaciones ideológicas de la campaña.

En su trayecto las huestes cruzadas debían poner cerco a dos fortificaciones que se encontraban en manos andalusíes, los castillos de Malagón y Calatrava. El primero de ellos, Malagón, fue capturado por la vanguardia cristiana, compuesta por los francos, que realizaron una matanza de todos los prisioneros. Acción extrema y poco común en la Península que generó roces entre los líderes cruzados. A continuación, el segundo bastión, Calatrava, fue capturado por el conjunto de los cruzados y Alfonso pactó la rendición perdonando la vida a los prisioneros. Este hecho aumentó a tal punto las tensiones entre los hispanos y los francos, que la gran mayoría de estos últimos abandonaron la campaña acusando a los hispanos de traición y amistad con los enemigos de Dios ${ }^{19}$. Según los cronistas, la deserción fue causada por acción del demonio, quien contaminó el corazón de los ultramontanos, haciéndolos abandonar la causa divina:

"Set quoniam humani generis inimicus nos cessat christianis actibus inuidere, misit Sathan in exercitum caricatis et corda emulancium conturbauit, et qui ad certamen fidei se accinxxerant, retrorsum a bono proposito abierunt. Omnes enim fere ultramontani comuni proposito statuerunt ut relictis crucis signaculis, omissis etaim belli laboribus, ad propria remearent" (Jiménez de Rada 1989 [s. XIII], VIII. 6: 265 $)^{20}$.

Luego, Alfonso X incluyó el relato en su Crónica General, agregándole más detalles en relación a que los ultramontanos, influenciados por el diablo, conspiraron para desertar de la campaña:

"Entre tod esto, porque ell enemigo de los omnes, et este el diablo, que nunca queda de inuidiar los buenos fechos de los omnes, metiosse en la huste de los fieles de Cristo et de la su caridad, et conturuio

19 Actualmente, diversos especialistas atribuyen la deserción de los ultramontanos a un conjunto de factores, tales como las penurias climáticas, los problemas de abastecimiento y las diferencias ente los caudillos en relación al trato dado a los musulmanes. (Al respecto ver García Fitz, 2008).

20 "Pero como el enemigo del género humano no deja de malquerer las obras cristianas, introdujo a Satán en el ejército de caridad y encizañó los corazones envidiosos; y quienes se habían aprestado para la contienda de la fe dieron marcha atrás en sus buenas intenciones. Pues casi todos los ultramontanos, dejadas las enseñas de la cruz, abandonados también los trabajos de la batalla, tomaron en común la determinación de regresar a sus tierras." (Jimenez de Rada, 1989 [s.XIII] VIII, 6: 314). 
los coraçones de los enuidiosos que se auien guisado pora yr a esta batalla. Et fizolos arredar de yr, et fizoles desuiar de la buena postura que auien fecha: ca por la mayor parte todos los trasmontanos de comunal postura establesçieron que tolliessen las sennales de la cruç que auien tomadas de que se cruçaran pora esta batalla, et que dexassen los trabaios de su lit, et se tornassen pora sus tierras" (Alfonso X, 1977 [s.XIII], 1015: 696).

Estas explicaciones providencialistas deben ser comprendidas en razón de algunos hechos que se infieren de las crónicas, y que se encuentran relacionados con el discurso validador de la guerra y la política peninsular. Primero, destacar el providencialismo presente en la campaña, ya que sólo una obra querida por Dios podría ser sujeto de una acción tan claramente diabólica, como la deserción de la cruzada, con la cual el Mal debilitaba a los cristianos. Al mismo tiempo, es posible concluir que la deserción de los ultramontanos sirvió a los intereses hispanos, puesto que sin ellos la victoria fue de exclusiva responsabilidad de los peninsulares -en especial de Castilla y su rey-, que habían organizado y financiado la campaña, conformando ahora el grueso de las tropas. La gloria sería así para Alfonso VIII y su reino, desligando su triunfo de la participación extranjera y desmereciendo a los francos, que en el Pseudo Turpin despreciaron a los peninsulares ${ }^{21}$.

Pese a la deserción del contingente ultrapirenaico, los cruzados hispanos continuaron su avance, llegando al paso de La Losa, el que fue bloqueado por los musulmanes. Ante la imposibilidad de avanzar se produjo una crisis entre los cristianos, cundió el desánimo y las divisiones. Es en este contexto que se produce el milagro más característico de la campaña y presente en todas las crónicas, aunque con matices.

Los relatos concuerdan que, mientras los caudillos cristianos discutían qué hacer, apareció un hombre al que califican de simple, un pastor, que pidió ser recibido por Alfonso VIII. En la reunión el hombre le habla al rey de un paso desconocido y no vigilado. El monarca envía una avanzada a corroborar la información y a ocupar el paso, por el que luego pudo pasar el ejército cristiano. Luego de ello el pastor desapareció misteriosamente.

No pasa mucho tiempo para que la figura de este hombre se rodeara de un aura milagrosa, pasando de ser un simple pastor, en los primeros relatos, a un enviado de Dios, para finalmente, en las fuentes más tardías,

21 Destacamos que, según las crónicas, los ultramontanos no fueron objeto de algún tipo de castigo divino por su deserción. Pareciera que toda su sanción fue no haber participado de la victoria y quedar señalados como traidores a sus votos y ajenos a la gloria alcanzada por los hispanos. 
ser identificado como un ángel mensajero, a semejanza de algunos episodios bíblicos. Alfonso VIII se refiere brevemente a él en su carta al Papa: "[...] nuestros magnates que iban en la vanguardia, guiados por un rústico que Dios nos envió impensadamente, encontraron allí mismo otro paso bastante fácil" (Gonzales, 1960: 566). Por su parte Lucas de Tuy, al referirse a él dice: "[...] presentose por divina inspiración al rey Alfonso un hombre, a modo de pastor de ovejas, que les enseñó un camino ancho" (Lucas de Tuy, 1926 [s. XIII], IV, 83: 415). Según Jiménez de Rada, era un hombre simple que "[...] resultó cierto como un enviado de Dios, que se sirve de las escorias del mundo [...]" (Jiménez de Rada, 1989 [s. XIII], VIII, 8: 318). Por su parte la Crónica Latina afirma que: "Se cree por los que juzgan con rectitud que no era 'un puro hombre', sino alguna virtud divina, que en tanta angustia, ayudó al pueblo cristiano, ya que por una parte, tantos adalides, tantos pastores, tantos hermanos de Calatrava discurrían a menudo por aquellos lugares y, sin embargo, ninguno de ellos sabía algo de aquel lugar, y por otra, no compareció posteriormente el pastor" (Crónica Latina de los Reyes de Castilla, 1999 [s. XIII], 23: 52), dando a entender que él camino fue abierto por Dios. De forma más tardía, Alfonso X en su Crónica General es más preciso y dice "assi Dios omnipotent, por cuya gracia spiritual se enderesçaua el fecho, enui alli entonçes al rey don Alffonsso un omne del pueblo, assaz uil de uestido et de persona" (Alfonso X, 1977 [s.XIII], 1016: 698). Finalmente, la Crónica de Veinte Reyes afirma. "Cuenta la estoria que ellos estando en este pensamiento, llegó vn omne bueno por la merçed de Dios, en semejança de pastor, que demandaua por los rreyes amuy gran priesa. Mas commo quier quel pastor semejase, çierto era ángel mandadero de Dios." (Crónica de Veinte Reyes, 1991, [s.XIII], XIII, 31: 283).

Esencialmente el episodio del pastor puede interpretarse como que la aparición de este personaje, un hombre humilde, rústico y simple, permite la continuación de la campaña y levanta el ánimo de los cristianos, todas ellas razones para asociar al personaje con un enviado de Dios, que de esta manera demostraba su beneplácito con la cruzada y sus líderes. No obstante, ninguno de los autores profundiza mucho en el personaje, ya que lo realmente importante fue su providencial aparición y la información que portaba, más que su identidad.

Es de destacar que algunos autores también han interpretado esta figura de baja condición como una señal de Dios para infundir humildad a los reyes cristianos y recordarles el mensaje de Cristo sobre los pequeños destinados a grandes cosas (García Pardo, 2002: 215-228). Ello en la línea del pensamiento providencialista medieval, construido sobre los relatos bíblicos, como son la historia veterotestamentaria de David (Samuel, I 16:1 y ss.) las Bienaventuranzas (Mateo 5:3-12, Lucas 6:20-23) y el relato de Mateo 20:16. 


\section{La batalla y sus milagros}

Superados los obstáculos, el domingo 15 de julio de 1212, en vísperas de la batalla, los obispos y clérigos recorrieron el campamento exhortando a los guerreros cristianos, reiterándoles las indulgencias de las cruzadas y amenazando con la excomunión a aquellos que dejasen el combate para recoger el botín (Crónica Latina de los Reyes de Castilla, 1999 [s. XIII], 24: 61-62. Crónica de Veinte Reyes, 1991 [s. XIII], XIII, 31: 284).

Que las arengas y las instrucciones de cómo comportarse en la lucha fuesen dadas por los clérigos y no por los reyes, confirma el espíritu cruzado de la campaña, puesto que ellos como jefes espirituales recuerdan las recompensas celestiales y pueden disponer de las gracias espirituales concedidas por Inocencio III.

Durante estas operaciones, según la Crónica de Veinte Reyes, se produce un nuevo y significativo portento para sacralizar la campaña y elevar el ánimo de los cruzados: "aparece en el cielo una cruz muy hermosa de oro y muchos colores que los cristianos vieron y tomaron como buena señal" (Crónica de Veinte Reyes, 1991 [s. XIII], XIII, 32: 284).

Finalmente el lunes 16 de julio de 1212, ambos ejércitos se enfrentaron. Después de un duro combate los cristianos rompieron las líneas almohades y las fuerzas musulmanas huyeron en desbandada.

De esta manera, la jornada fue una victoria completa para los cristianos, aunque parecía que ésta por sí misma no bastaba para resarcir a Alfonso de su anterior derrota; fue así que los relatos se complementaron con distintos portentos que resaltaban las características providenciales del triunfo ante los poderosos almohades. De esa forma, el triunfo sería de Dios, por intermedio de los hombres.

Es así como se relatan varios milagros, por ejemplo, uno narrado en las crónicas de Jiménez de Rada y Alfonso X: un canónigo toledano que llevaba la cruz del Arzobispo, cruzó todo el campo musulmán, pasando por una Iluvia de flechas sin que ninguna de ellas lo alcanzara a él o la cruz (Jiménez de Rada, 1989 [s. XIII], VIII, 10: 322. Alfonso X, 1977 [s. XIII], 1019: 702).

Al ver la batalla perdida, Miramamolín abandona el campo y los musulmanes que escapan son perseguidos y masacrados por los cristianos, puesto que según Jiménez de Rada "no queriendo los nuestros poner límites a la gracia de Dios [...]" (Jiménez de Rada, 1989 [s. XIII], VIII, 11: 323).

Obtenida la victoria, los clérigos cristianos entonan himnos de gracia, para luego proceder a recoger el inmenso botín, momento en que se revela otro milagro: "A su vez, los agarenos que fueron hallados junto al ya mencionado 
palenque [...] cosa sorprendente, aunque quedaron tremendamente mutilados y ya habían sufrido el pillaje de los pobres, no se podía descubrir en todo el campo ni un rastro de sangre" (Jiménez de Rada, 1989 [s. XIII], VIII, 10: 322. Alfonso X, 1977 [s. XIII], 1019: 702-703). Lo que bien podría significar la intención de los cronistas por demostrar que fue una victoria limpia, pura, que no contaminó la tierra sagrada de Hispania con la sangre de los musulmanes.

Asimismo, las crónicas también atribuyen a la intervención de la Providencia las exageradas cifras de muerte de musulmanes -en algunas fuentes más de cien mil- en comparación a los pocos caídos en el bando cristiano -no más de cien- (Jiménez de Rada, 1989 [s. XIII], VIII, 10: 323. Alvira, 1995: 414). Los cronistas ven en estas cifras la intervención protectora de Dios y las utilizan para reforzar el discurso que convertía a los guerreros cristianos en paladines de la fe, en oposición a los musulmanes, que producto de su maldad, sufrieron el castigo espiritual, como lo relata la Crónica Latina: los "moros" caídos "in profundum inferni descenderunt" (Crónica Latina de los Reyes de Castilla, 1999 [s. XIII], 25: 62).

\section{Después de la batalla}

Asegurado el triunfo, los cruzados decidieron aprovechar su ventaja estratégica y abandonado el campo de batalla se encaminaron a la población de úbeda para cercarla. Allí los defensores ofrecieron una fianza de piezas de oro para rescatar la ciudad (la cantidad del monto ofrecido varía según las fuentes). Inicialmente el rescate tentó a los reyes cristianos, pero los arzobispos y demás autoridades religiosas lo prohíben tajantemente, puesto que ello sería contrario a los principios cruzados, por lo que la ciudad finalmente fue capturada por asalto y su población sometida a cautiverio (Jiménez de Rada, 1989 [s. XIII], VIII, 12:325. Crónica Latina de los Reyes de Castilla, 1999 [s. XIII], 25: 63).

A continuación las fuentes dan a entender que la codicia demostrada por los reyes cristianos, sumado al hecho de que se vanagloriaban de su victoria, motivó la última intervención divina en la campaña; una peste azotó a la hueste cristiana, obligándola a abandonar la campaña y regresar a Toledo (Crónica Latina de los Reyes de Castilla, 1999 [s. XIII], 25: 55. Alfonso X, 1977 [s. XIII], 1021: 705). Jiménez de Rada es bastante explícito al respecto al afirmar que:

"Y como ya la gracia de Dios se estaba marchitando por causa de los excesos de los hombres, los cristianos, presa de su avaricia, se dedicaban a los delitos y los robos, por lo que el Señor les colocó un freno en sus bocas y los golpeó con enfermedades a ellos y sus animales de tiro, y apenas había en las tiendas quien pudiera atender a su camarada o a su señor." (Jiménez de Rada, 1989 [s. XIII], VIII, 12: 325). 
De esta forma Dios castigaba la falta de humildad y la codicia de los caudillos cristianos, al atribuirse como propia una victoria que Él les otorgó.

Pese a este último revés, las crónicas cierran el capítulo de Las Navas señalándolo como una gran victoria cristiana, y una señal inequívoca de la justicia providencial de la causa de Reconquista.

\section{A modo de conclusión}

Los relatos en torno a la batalla nos permiten aproximarnos al uso de la guerra religiosa como instrumento diplomático y a las crónicas como instrumentos al servicio de la monarquía y sus intereses.

También nos revelan un aspecto más radical de la guerra en Hispania, un extremismo relacionado con la idea de cruzada y que podemos apreciar en la matanza de Malagón, las amenazas de excomulgar a los que por recoger botín dejen de matar a los musulmanes y la intransigencia frente a la oferta de los defensores de Úbeda.

Junto a lo anterior, respecto a la concepción providencialista de la guerra, Las Navas nos demuestra importantes cambios, principalmente en lo referido a las figuras celestes. En batallas anteriores de la Reconquista, los cronistas solían incluir la participación de mensajeros divinos o guerreros santos, como los ya conocidos casos de Santiago e Isidoro. También eran comunes los sueños premonitorios, donde los enviados de Dios advertían o instruían a los líderes cristianos. En resumen, entre los siglos VIII y X, y en menor medida en el siglo Xl, las intervenciones providencialistas fueron directas y presentadas de manera indiscutible. Por el contrario, en el caso de las Navas, la intervención providencialista es mostrada de manera distinta; ejemplo de ello es que el gran milagro de la batalla, el episodio del pastor, no genera consenso en los cronistas en cuanto a su naturaleza. Sus interpretaciones van desde su consideración como un hombre humilde, hasta la de un ángel, versión que gana adeptos a medida que las crónicas se alejan del suceso. Donde sí coinciden los cronistas, es en que la afortunada intervención se debió a un designio divino. Sin embargo, lo realmente interesante a nuestro parecer, es que este "mensajero" solamente se limita a señalar un camino, dejando a los cruzados la decisión de tomarlo y proseguir la campaña ${ }^{22}$.

22 A diferencia de otras apariciones celestes, el pastor no da instrucciones ni consejos, ni siquiera dirige palabras de ánimo a los apesadumbrados reyes cristianos como, por ejemplo, lo hacía Isidoro o Santiago. Al respecto reiteramos que no es nuestra intención afirmar que el providencialismo desapareció de las crónicas y creencias populares en el siglo XIII, sino que éste fue mutando. Los santos siguieron apareciendo, como en el caso de la ayuda que Santiago otorgó a Alfonso IX en la batalla de Alfanje, pero sus apariciones directas como 
Esta relativa pérdida de la importancia del providencialismo manifiesto pudo deberse a múltiples factores, entre los que se pueden considerar el cambio de mentalidad que manifiestan los cronistas a partir del siglo XII. Este cambio se refleja en un mayor uso de fuentes diplomáticas y una posición más cercana al poder político, ya que no hay que olvidar que la mayoría de las crónicas de la batalla fueron escritas por personajes contemporáneos de la misma y que además experimentaron el proceso de unificación de Castilla y León en 1230.

Entonces, la batalla de las Navas refleja una nueva visión del providencialismo de cruzada, ya que si bien los cronistas insisten sobre la intervención divina, a fin de cuentas son los hombres quienes deciden los cursos a seguir, siendo ellos los que luchan contra los enemigos de Dios, aunque inspirados por sus señales.

A nuestro juicio, esta concepción va en la misma línea que los otros portentos observados en la batalla de Las Navas, puesto que los milagros quedan reducidos prácticamente a hechos anecdóticos, como los abrojos que no dañan, la aparición de una cruz en el cielo, el estandarte invicto de la Catedral, o la ausencia de sangre en el campo de batalla; es decir, se trata de hechos secundarios que no afectan el desarrollo del combate ni las decisiones estratégicas de los combatientes. De esta forma, la interpretación de la victoria nos lleva a conjeturar que es una intención por parte de los cronistas de mantener el discurso providencialista, pero dirigiendo el peso de las acciones a la voluntad humana. Dios y su poder rodea toda la narración de la batalla, pero en su centro se encuentra Alfonso VIII, que como simple hombre es el encargado de dirigir la cruzada.

El rey es mostrado como una criatura sujeta al pecado y, en especial, a la vanidad, puesto que los cronistas no ocultan sus flaquezas -como sus dudas ante el bloqueo del paso de La Losa-, aunque al mismo tiempo narran sus virtudes, su generosidad y valor. Entonces el eje de la acción ya no es la Providencia sino el rey, que como mortal debe elegir los caminos que Dios pone a su disposición. El monarca se convierte así en un nuevo modelo a seguir, en un hombre inspirado por Dios, pero esencialmente un mortal con virtudes y defectos que enfrenta obstáculos que es capaz de superar gracias a la ayuda de la potestad divina.

En síntesis, se puede afirmar que a partir del siglo XII, y ya decididamente en el siglo XIII, las crónicas restringen cada vez más los episodios providencialistas. En textos como las crónicas de Lucas de Tuy, Jiménez de Rada o la Crónica

blancos guerreros se hicieron cada vez más esporádicas. En cambio, se refuerza la imagen del soberano, que poseído por el espíritu de Dios, o siguiendo los consejos de la Providencia, realiza actos gloriosos, como la conquista de Córdoba por Fernando III. 
General se puede apreciar este cambio, puesto que en los episodios anteriores a su redacción se narran acciones providencialistas directas, como las apariciones de santos, mensajeros y combatientes divinos. Sin embargo, cuando los autores narran episodios contemporáneos a ellos, estas acciones directas se reducen, al punto que en sucesos como las conquistas de Fernando III, los milagros y otros prodigios prácticamente desaparecen o no son relevantes.

De esta manera, el rey se presenta como el sujeto principal de la narración, trasmitiéndose la idea de que sus acciones eran validadas y legitimadas por la Providencia. Así, la instrumentalización de la religiosidad al servicio de los fines políticos y militares de la Reconquista castellana se mantenía, aunque de un modo que se adaptaba mejor a los nuevos tiempos de fortalecimiento del poder de las monarquías.

\section{Referencias bibliográficas}

\section{Fuentes primarias}

Alfonso X (1977). Primera Crónica General de España. Editada por Ramón Menéndez Pidal con un estudio actualizador de Diego Catalán, $2^{\circ}$ tomo de la tercera reimpresión. Madrid: Gredos.

Biblia de Jerusalén (1975). Bilbao: Desclée de Brouwer.

Crónica de Veinte Reyes (1991). Burgos: Ayuntamiento de Burgos.

Crónica Latina de los Reyes de Castilla (1999). Edición de Luis Charlo Brea, Madrid: Akal.

De Tuy, L. (1926). Crónica de España. Primera edición del texto romanceado, conforme a una copia de la Academia preparada y prologada por Julio Puyol. Madrid.

Gonzales, J. (1960). El reino de Castilla en la época de Alfonso VIII, III Documentos. Madrid: Consejo Superior de Investigaciones Científicas, Escuela de Estudios Medievales.

Jiménez de Rada, R. (1989). Historia de los hechos de España, Introducción, traducción, notas e índices de Juan Fernández Valverde. Madrid: Alianza.

Los anales toledanos I y II (1993). Edición de Julio Porres Martín-Cleto, Toledo: Instituto provincial de Investigaciones y Estudios Toledanos, Diputación Provincial de Toledo.

Ximenii de Rada, R. (1988). Opera Omnia, Pars I, Historia de revus Hispaniae. Corpus Christianorum, Continuatio Mediaevalis, LXXII. Turnholti: Typographi Brepols Editores Pontificii. 


\section{Fuentes secundarias}

Alvar, C. (1977). La poesía trovadoresca en España y Portugal. Madrid: Cupsa, D.L.

Alvira, M. (1995). "La muerte del enemigo en el Pleno Medioevo: cifras e ideología (el modelo de las Navas de Tolosa)", en Hispania: Revista Española de Historia, 190. LV/2, pp. 403-424.

Alvira, M. (1996). "La imagen del Miramamolín al - Nasir (1199-1213) en las fuentes cristianas del siglo XIII", en Anuario de Estudios Medievales, Vol. 26/2, pp. 1003-1030.

Alvira, M. (1997). "El desafío del Miramamolín antes de la batalla de Las Navas de Tolosa (1212): Fuentes, datación y posibles orígenes", en al-Qantara: Revista de estudios árabes, Vol. 18, 1, pp. 463-490.

Alvira, M. (2006). "Del sepulcro y los sarracenos meridionales a los herejes occidentales", en Baloup, D. y P. Josserand (Editores), Regards Croisés sur la Guerre Sainte. Guerre, Idéologie et Religion Dans L'espace Méditerranéen Latin (XI-XIII Siècle). CNRS-Université de Toulouse-Le Mirail.

Cardini, F. (2003). "Guerra y Cruzada", en Le Goff, J. Y J.C. Schmitt (Editores), Diccionario razonado del Occidente medieval, Madrid: Akal.

Contamine, P. (1984). La Guerra en la Edad Media, Barcelona: Labor.

García F. (2003). La Edad Media. Guerra e ideología, justificaciones jurídicas y religiosas. Madrid: Sílex.

García, A. (1985). Iglesia, Sociedad y Derecho. Salamanca: Universidad Pontificia de Salamanca.

García, F. (2002). Relaciones Políticas y Guerra. La experiencia castellano-leonesa frente al Islam. Siglos XI-XIII. Sevilla: Universidad de Sevilla.

García, F. (1988). "La conquista de Andalucía en la cronística castellana del siglo XIII: Las mentalidades historiográficas en los relatos de la conquista", en Cabrera, E., Andalucía entre Oriente y Occidente (1236-1492), Actas del V Coloquio Internacional de Historia Medieval de Andalucía, Córdoba: Excma. Diputación Provincial de Córdoba.

García, F. (2001). Castilla y León frente al Islam: Estrategias de expansión y Tácticas militares (Siglos XI - XIII). Sevilla: Universidad de Sevilla.

García, F. (2008). Las Navas de Tolosa. Barcelona: Ariel.

García, M. (2002). "El pastor de Las Navas de Tolosa. La realidad y la leyenda", en Historia, tradiciones y leyendas en la frontera: IV Estudios de Frontera: Congreso celebrado en Alcalá la Real en noviembre de 2001: Homenaje a Don Enrique Toral y Peñaranda. Coordinado por F. Toro Ceballos y J. Rodríguez Molina. 
García, R. (1967). Historia de la Iglesia Católica en sus cuatro grandes edades: Antigua, Media, Nueva y Moderna. Madrid: Editorial Católica.

Goñi, J. (1958). Historia de la Bula de Cruzada en España. Vitoria: Editorial del Seminario.

Hindley, G. (2005). Las Cruzadas, peregrinaje armado y guerra santa. Buenos Aires. Ediciones B.

Huici, A. (1956). Las grandes batallas de la Reconquista durante las invasiones africanas (Almorávides, Almohades y Benimerines). Madrid: Instituto de Estudios Africanos, Consejo Superior de Investigaciones Científicas.

Keen, M. (2005). Historia de la guerra en la Edad Media. Madrid: Antonio Machado.

Riley-Smith, J. (2012). ¿Qué fueron las cruzadas? Barcelona: Acantilado.

Rodríguez, A. (1988). "La política eclesiástica de la monarquía castellano-leonesa durante el reinado de Fernando III (1217-1252)", en Hispania Revista Española de Historia, № 168, pp. 7-48.

Rodríguez, J. (1994). "Fernando Ill y sus campañas cruzadas en el contexto cruzado europeo, 1217-1252", en Archivo Hispalense, 234-36, pp. 205-217.

Rodríguez, J. (2002). "Cruzados y fronterizos. Discusión sobre el carácter cruzado de la guerra en la frontera, 1214-1314", en Toro Ceballos, F. y J. Rodríguez Molina (coordinadores). III Estudios de Frontera, Jaén, Diputación.

Russell, F. (1977). The Just War in the Middle Ages. Cambridge: Cambridge University Press.

Vara, C. (1999). El lunes de Las Navas, Jaén: Universidad de Jaén. 